\title{
Unifying vs. Diversifying Approaches and Relevant Reflection on Translation of Cultural Keywords: Based on the Case Analysis of Junzi and its Counterpart Xiaoren
}

\author{
Pang Xiucheng \\ English Department, School of Foreign Languages, Northeast Normal University, China
}

Copyright $(\mathcal{C} 2015$ by authors, all rights reserved. Authors agree that this article remains permanently open access under the terms of the Creative Commons Attribution License 4.0 International License.

\begin{abstract}
In the Analects of Confucius, the Bible of Chinese people, junzi and xiaoren, are two contrasting cultural keywords respectively with multiple meanings. There are a variety of target terms for each of them through the interactions between suggestiveness and articulateness, translatability and untranslatability, and between comparability and incommensurability. These target terms may establish in the target culture different conceptual paradigms about the source culture. The strategies of translating cultural keywords should draw support from the history of thoughts and concepts. The methodology needs to be discussed against the cultural background. Unifying these meanings with one term and diversifying the original word with multiple terms are two contradictory but complementary approaches. Through case analysis, this paper aims at presenting how and why the two approaches are used, what are the relationships between them and what insights we can get from the case study in terms of cultural construction and intercultural communication.
\end{abstract}

Keywords Translated Terms, Cultural Keywords, Unifying Approach, Diversifying Approach, Junzi, Xiaoren

\section{Introduction}

Cultural keywords like Junzi (君子)and xiaoren (小人) are uncertain, polysemous in connotation. One of the traditional principles of translation of names or terms is that of uniformity, that is, to unify all the translated terms for a ordinary name or term, a technical or semi-technical term, an academic name or term. Translators are inclined to discover an infallible and ever-lasting name or term in the target language for the one to be translated. This idealistic position originates from the universalist views of language, and dates back to the instrumentalism in sci-tech communication. We admit the necessity and effectiveness of the uniformity in sci-tech circles. But when it comes to the translation of cultural keywords, things become more complicated even than those of social sciences. Actually, any translated term for cultural keywords, may highlight one or two meanings of the keyword, but conceal the rest or impose upon the keyword extra meanings it does not originally have, but any translated term for it may be reasonable, necessary and constructive, though inadequate.

Traditionally there exist two approaches in this regard, unifying the meanings in the keyword with one term or diversifying the keyword with multiple terms, with the former seemingly being preferable and justified according to the principle mentioned above. The two contradictory pursuits, based not convergent and divergent thinking respectively, compete against each other among the translators, but fewer of them account for their preference for one over the other. Although there are established terms for the keyword, the discovery or creation of an infallible and ever-lasting translated terms is still tantalizing. To bring about the similar suggestiveness in the target text, the translator is encouraged to construct a term capable to comprise as many original meanings as possible. The diversifying-purpose translators may be prompted by presenting the multifold meanings of a cultural keyword. How and why are the two approaches used in the translation of cultural keywords? What effects do the diversifying approach bring about on target readers? To what extent do the two approaches have something to do with constructing or reshaping the national identity of the source culture or the target? How do they have joint function in the cross-cultural exchange? Is it possible to examine the problems from Chinese perspective? All these need to be discussed based on the case analysis of cultural keyword translation.

\section{The Analysis of Conceptual Features and Changes of Junzi and Xiaoren}

Junzi and xiaoren, as a pair of cultural symbols and different from pure technical terms, have long permeated 
throughout the mentalities of Chinese people, and hence help to form the cultural values and historical consciousness of the social members. Because of their rich connotation, they are characterized by their indispensability, irreplaceability and untranslatability. The untranslatability is not in the linguistic meaning, but in the cultural sense. It "results not from the lack of corresponding terms between different languages, but more from the historical process of conceptualization and traditional association, giving rise to the increase of special elements in concepts." [6:p16]

Diachronically, the term junzi has experienced various changes and developed a number of derivative meanings. Scholars have numerous understandings of the word from different perspectives, social, ethical, political or aesthetical. Translators hence have proposed diversified terms for it. In The Analects the term has transformed from the status junzi (di wei jun zi 地位君子) to the wisdom junzi (zhihui junzi 智 慧君子) and the morality junzi(dao de jun zi 道德君子). Therefore, the word has been endowed with hierarchical connotation. Besides,"Confucius distinguished two types of ideal personalities: shengren (sage 圣人) and junzi, with the former being superior to the latter and being the perfect example and highest status of personality." [3: p78]To impel people to move upward, Confucius set an ideal personality shengren over junzi. The former is the exemplary person of the latter. And the latter accordingly is the exemplary person of commoners. The essence of junzi is ren(benevolence 仁) embodied by principles of humanity and rationality. Junzi, in contrast with xiaoren, steps up to the moral and intellectual status of shengren through self-cultivation in knowledge and practice.

In order to justify itself, junzi has to establish a hermeneutical sign relations with other concepts such as renren(benevolent person 仁人), daren (great person 大人), xianren(wise and virtuous person 贤人), shanren(charitable person 善人), chengren(complete person 成人) and shi(commendable person 士). D.I.Hall and R. T. Ames [14:p188]believed that all these terms were different aspects of an individual's progress in the pursuit of becoming shengren(sage). Therefore, junzi, along with its interpretations or the above sign relations, exists between the two poles of the moral scale from shengren to xiaoren. It can be examined from within( benevolence, righteousness, wisdom) and without (practice, propriety, words). Its features become the unities of neisheng (sageliness within ) and waiwang (kingliness without), being refined and being simple, self-cultivation and writing style, learning and doing, and knowledge and practice, etc. The internal composition of junzi is the integration of cognition, affection and volition, combination of humanism and rationalism, the unanimity of the true, the good and the beautiful. The external embodiment is the harmonious presentation of all the relationships by self-transcendence. Just as Peng Feng[29] says: "The ideal personality of Confucianism is a synthesis which contains all contradictory relationships."

Besides the basic meanings( benevolence, righteousness, propriety and wisdom), there are still others which are expected from junzi codified with different Chinese characters, such as zhong (loyalty), yong (bravery), xiao (filial piety), $t i$ (respect for one's elder brothers), shu (forgiveness), gong (respectfulness) kuan (tolerance), xin (trustworthiness), $\min ($ resourcefulness), hui(generosity), zhizu(being poor but content), gaiguo(being ready to correct one's mistakes), etc. Even $l i$ (propriety) itself contains a number of connotative meanings, such as gravity, seriousness, gentleness, slowness in words, dignity, modesty, peacefulness, etc. Moreover, Junzi with its manifold meanings stands in contrast with its opposite group with different concepts except xiaoren (petty person 小人), such as bifu (mean creature 鄙夫), yeren (rustics 野人), $\min$ (the people 民). Within the member concepts in each group are interrelated within and differentiated without. Concepts like the above "as expressions of epistemic thoughts should be investigated in the concept network "[7:p13]. Deconstructionism can help us in understanding deviations between signifiers and signified, but it prevents us from understanding the possibility of these concepts. No senses and meanings can be perceived without putting them in their concept group. Only by means of historical-cultural mode of thinking, can a cross-cultural discourse system be reconstructed in the target culture.

It has been widely believed that the personality connotations in junzi are relatively stable, leading to the adoption of unifying approach in its translation. Diachronically, the keyword has experienced various changes from its original meanings to its transfered meanings. It is context-dependent, with these meanings respectively referring to the class of aristocracy including Son of Heaven, dukes or princes under the Son of Heaven or son of a ruler, honorable persons, husbands or even persons of noble mind which was largely expounded by Confucius later. In Confucius times, junzi had started to part with such meanings as blood lineage, position or wealth, or as a social concept denoting an aristocratic or ruling class member. It had partly evolved into a moral concept with social or political responsibility. "To Confucius, the personality of $j u n z i$ is characterized by strong flavor of aristocracy on the one hand, and the constancy that exempted from the changes of his external circumstances on the other", "...it after all entails positive meanings that resist social hierarchy and power ."[3:p77, 78]Up to the times of Confucius and Mencius, junzi had completed its transformation into a general appellation with both social meanings ( general reference of rulers and male nobles) and moral connotation, in contrast with xiaoren ("petty person" or "uncivilized man").

Later on, junzi, especially used together or in contrast with xiaoren, refers to outstanding figures with both talent and morality. And this usage has become common ever since, covering the following situations. First, junzi has nothing to do with class origin or family background. Ban $\mathrm{Gu}$, a historian of Han Dynasty, explained in his book Bai Hu 
Tong• Hao(Comprehensive Discussions in the White Tiger Hall) : "What is junzi? It is a title of morality. Jun means group while $z i$ is the general address for male adults."[27]Wang Anshi, a statesman of Song Dynasty, said in his Junzi Zhai Ji(Account of Junzi Sanctum) : "All those who have morality are generally called junzi." [27] Secondly, junzi is not judged by wealth. "The Master said, "He who aims to be a man of complete virtue, in his food does not seek to gratify his appetite, nor in his dwelling place does he seek the appliances of ease."'[21:1.14, p143,144] "The Master said, 'The superior man may indeed have to endure want, but the mean man, when he is in want, gives way to unbridled license."'[21:15.3, p294] Thirdly, junzi may not be in political power although he is the most ideal person to be a ruler. "The wise and able men( junzi, my note) are kept in obscurity, but the vicious and mean men(xiaoren, my note) occupied the official positions."[26: p306, 307] This shows that junzi may not necessarily hold a position in the government. The question of "whether junzi seeks for a position in the court" reveals that junzi may live in freedom to be an official or a civilian ( a member of the ruled). It is clear that junzi may not necessarily be an official, but an official should be junzi. Lastly, junzi should be a scholar or a person who is willing to learn while a scholar who is good at insignificant skills may not be junzi. Confucius said: "Be junziru(a honorable scholar like junzi) and not xiaorenru(a petty-minded pedant)." Qian Mu[31:p152], a well-known historian of modern China, explained that xiaorenru(a fool while trying to be an encyclopaedic man of culture) is the person who "is absorbed in classics but ignores the manners and morals of the time."

Similar to junzi, xiaoren is just like a scale plate along which people slide according to their vision and performance. At the bottom are the mean persons, at the top the commoners with simple but unenlightened mind and in the middle the people with the petty or shallow mind. Confucius once described one of his disciples Fan Chi as xiaoren because the latter asked his Master to teach how to farm [21:13.4, p264,265]. Xiaoren also has the potentiality to grow into junzi if they become strong enough in will power. As American scholars David L.Hall and Roger T. Ames explained: "An individual through some lack of effort or insight, fails to develop towards 'authoritative personhood' is a 'retarded individual' (hsiaoren 小人 ).” [14:p84]

Shi (often translated into an intellectual or a scholar 士) originally refers to a knight(the lowest in feudal military rank, higher than common soldiers), or a title for a man whose status was between that of the nobles and the commoners. Fan Wenlan[5:p110、144、213-214], a historian, and Fei Xiaotong[8:p25,45,176], a sociologist, had deeply probed into shi as a class of ancient Chinese society. Fung Yu-lan held that shi is a class of "scholars" "who did not engage in any kind of productive activity, but depended entirely upon others for their support." [10:p52]In Confucius Times, members of this class engage in "only two kinds of activity: that of holding government office and that of teaching." [10:p52, 54] In The Analects, roughly referring to the upholders of Confucianism or scholars and literary people in general. Therefore, it can be defined as a collection of intellectuals or learned persons who are devoted to maintaining Confucian orthodox teachings. Confucius described shi as morally educated person with the same qualities of endurance and resolution as the soldier knight. [42:p34] The two concepts, junzi and shi are interwoven in many respects. Hence, the translation of junzi is also entangled with that of $s h i$, and junzi cannot be translated properly without better understanding its relationship with shi.

\section{Survey of the Translated Terms of Junzi and Xiaoren}

Junzi, rich in meaning, makes all their translated terms temporary substitutes. It is safe to say that in no language can we find or recreate equivalents for junzi in its target culture. Scholars and translators have presented numerous controversial understandings of the keyword from different perspectives, social, political, intelligent or moral. According to Bian Lihong's survey [2], the translated terms for junzi in Confucius Analects have exceeded thirties. But the number in reality might be far beyond this because Legge alone created more than 20 translated terms for junzi.

Chinese and its culture justifiably make it both possible and impossible to translate its cultural keywords. Just as Karl-Henz Pohl[30:p107] put it, Chinese cultural pattern has the amazing ability of seeing things as mutually inclusive and "seeing identities where we are inclined to see differences." And for the same reason, their plurisignation ( $x$ u han shu $y i$ “虚涵数意”) or manifold meanings in one word have frustrated and also enlightened many who wish to find or create one perfect term once for all. Chinese people have long been accustomed to the semantic broadness in the keyword so that "they use it to talk about extensive things without feeling the lack of identity and uniformity."[36:p46] But the responsibility or the fate of the translator means he has to enter the "horizon of significance" $[33: p 52,53]$ and to understand against the unarticulated background so as to translate the untranslatable. This vision is effective to observe both bilingual and intralingual translation of cultural keywords.

\subsection{Legge's Diversifying Approach}

Junzi appears 107 times in Analects.[16:p142 143]Legge translated it into different terms. His version The Confucian Analects is one of the most popular versions in the West. The variation of translated terms for junzi in different context reveals that Legge used the method of exegesis to translate the manifold meanings of the keyword and determined one term by its contexts(sui wen jian yi 随文见义). For his approach, he explained, "It is a technical term in Chinese 
moral writers, for which there is no exact correspondency in English, and which cannot be rendered always in the same way.[21:p138]Among the translated terms for junzi ,superior man is especially frequently used 77 times in total. The rest are used one or two times. The translated terms fall into above-mentioned three categories: 1 . the status junzi: superiors, a man in a superior station, the man of high station, a man in a superior situation, the person in authority, the man of high rank, those who are in high stations; 2. the wisdom junzi: the scholar、 the accomplished scholar; 3 . the morality junzi: a man of complete virtue、virtuous man、 the student of virtue, a man of virtue, men of superior virtue. There are also a combination of any two of the above three categories, such as a man of virtue and station, a man of real talent and virtue. In one sentence junzi are mentioned two times, but he unreasonably diversified them with "the student of virtue" and Chün-tsze respectively [21:p157]. Chün-tsze here is the only one instance of transliteration in his Confucian Analects. It is worth noting that except the one instance "accomplished gentleman." [21:p237] He did not use gentleman as many translators have done.

Legge seemed to be a worthy spokesman for Confucius, explaining the different conceptions and connotations for the word. He gave up the pursuit of one and only term for junzi. By diversifying the translated terms for $j u n z i$, he interpreted the different contextual meanings of the word. But when these terms are considered as a whole, they help to describe the silhouette of the word in its cultural ecosystem and contextually to discover or represent one or tow of its connotative meanings each time, social, political, intelligent or moral. But there are two side-effects of the diversifying approach. One is that the target readers may fail to know which word or phrase in the target text corresponds to junzi and not to other keywords. The other is the difficulty for the target readers to form an overall picture of the keyword. This certainly effaces the identity and peculiarity of junzi in the source culture. Legge frequently used "superior man" as a translated term for junzi, but this term is certainly not as comprehensive as junzi in the source culture. Besides it is misleading wherever it appears. In fact, "superior" has reduced junzi to social position, meaning "higher in class, rank or power". It also contains negative connotations such as arrogant, overbearing or indifferent. Therefore it is not in agreement with junzi in meaning.

The opposite "inferior" has been used to translate xiaoren. Besides its social meaning "lower in class, rank or power", its commentary meanings are much derogatory, which are low, secondary, poor in quality, greedy, or jealous. Both superior and inferior has derogatory meanings. And both of them have laid emphasis on the social aspects. As junzi is established as an ideal person through personification of virtues and xiaoren is the opposite, neither is the classification of social members, and both are two poles of moral continuum that are presented to people so that they will take them as reference to move upward. Here, the law of excluded middle cannot be used to distinguish people in the society. The moral or political meaning in the establishment of the two terms is to give a warning to all the people in the world not to fall or deteriorate. When we say a person is a junzi or xiaoren, we associate this judgment with their deeds because human beings are existence of dynamic improvement. Hence Legge's translated terms are in contradiction with the continuum which is the illustration of morality and not the classification of social classes, as is explained by the expression in the Fourth Act of the Chinese play TheYoung Mistress' Fan by Hong Shen: “I don't think that people in the society can be simply classified into two types: that of junzi and that of xiaoren." [27]

The problem of demarcation with other concepts immediate occurs as soon as the translated terms for junzi are established. Firstly, junzi may not necessarily be a ruler. If junzi is rendered by Legge as superiors, the person in authority or those who are in high stations, then it is difficult to distinguish junzi from shang(meaning rulers 上). Legge mixed up shang with junzi by translating into superiors as can be seen in the sentence "They are few who, being filial and fraternal, are fond of offending against their superiors." $[21: 1.2,138]$ And it is also hard to distinguish junzi and shang from shi( 士) and dafu(大夫) which he rendered the latter two keywords into officers and ministers respectively.[21:8.7,p210;14.21,p284] Secondly, junzi should be but may not necessarily be a scholar. It may refer to persons with wisdom or intelligence, but if it is translated into scholar, then it is undistinguishable with shi( 士). But Legge also translated shi into scholars.[21:4.9 p168;19.1 p339] In fact, in Analects, shi was educated and learned persons who took responsibility to maintain the orthodox teachings and therefore there are more reasons to translate it into scholars but not into knight that has strong flavor of Western culture. Moreover, Legge's approach leaves us in confusion by translating xian (virtuous 贤) into the superior as in "Which of the two, Shih or Shang, was the superior" [21:11.15,p242] and translating renzhe (仁者), renren (仁人) into the man of virtue. [21:6.22, p191; 15.9,p297] David Hall \&Roger Ames indicate junzi and renzhe are not independent categories but include each other [14:188] But they should be recoded with different terms in translation as they are different in source culture in terms of significance. In Analects, junzi is different from xianren (贤 人) and renzhe. Similarly, the translated terms for xiaoren are mixed up with such terms as $\min$ (the ruled 民), $p i f u$ (ordinary man 匹夫)、bifu(vulgar person 鄙夫, used as self-effacing word or a substitute for the ruled). Besides, xiaoren was described more contemptible when the translated term for it the mean man was chosen, because mean is only suitable to describe those who are at the bottom of the scale plate of xiaoren. In this case, the translated term superior cannot correspond only to inferior. It is safe to say that in Legge's Confucian Analects, his pictorial pattern does not correspond to that of Chinese culture.

In addition, the dichotomy of the morality genealogy does not mean there is no intermediate zone. Actually, most 
people are in the transitional area on the scale plate of spiritual progress. The plate is almost open-ended because there have been no strict definitions for junzi and xiaoren. The purpose of Confucius is to set up a dynamic criteria by which moral items such as benevolence, intelligence, bravery and others are constantly demonstrated. According to The Analects, the criteria for judgment of junzi are high. For example, Tsze-Lu asked what constituted junzi. Confucius explained about the double missions of junzi by saying that "He cultivates himself so as to give rest to others." "He cultivates himself so as to give rest to all the people...-even Yao and Shun were still solicitous about this." [21:14.42, p292] No one can perform all the tasks and functions mentioned in The Analects, but all can achieve some of the goals. To Confucius, Junzi is a person who aims at persistent self-development and demonstration of his moral growth though self-cultivation as well as social and political leadership. That is, he is the one who has perfected himself through a life-long engagement of self-cultivation or self-transcendence. However, to Confucius, anyone has the potentiality to realize some the virtues of junzi. Even people of low ranks and with the willingness to study and cultivate himself can become junzi. As Confucius said, 'Is virtue a thing remote? I wish to be virtuous, and lo! Virtue is at hand." $[21: 7.29, \mathrm{p} 204)$

\subsection{Gu Hongming's Diversifying Approach}

$\mathrm{Gu}$ Hongming[12], like Legge, took the approach of diversifying translated terms for junzi and xiaoren from three perspectives (social, intelligent and moral) or two of the perspectives combined. Social and moral perspectives are chosen alternatively, but the intellectual perspective is more frequented. In most cases, junzi is translated into a wise and good man (34 times) or a good and wise man (17times). Obviously, the two aspects of intelligence and morality are stressed. There are 26 times when a wise man is chosen to stand for junzi. [12:4.11, p369]A scholar and an educated man are also applied. There are only a few cases where moral translated terms are alone favored. They are a good man, a good moral man, a man of virtue, and a great man[12:17.21, p485]. Similarly, there are a few cases which manifests the aspect of position or power. They are the rulers, a ruler and superiors. [12:12.19, p437] Gentleman [12:13.3, p442] is also used and the total number of instances is 12 , which is not small compared with the one instance in Legge[21:237]. All the above translated terms cover three aspects of junzi, but the morality genealogy junzi and xiaoren is set up mainly according to wisdom.

Out of 24 times of xiaoren's occurrences, there are 15 times when Gu Hongming used a fool as the translated term for it, which is in agreement with his emphasis on wisdom in the translation of junzi. [12:14.24,p456] Besides, the translator also offered his translated terms from social hierarchical criteria. The people are used several times. [12: $17.4, \mathrm{p} 480]$ The rest are a man of the people; a petty-minded man; a dogged, stubborn little gentleman; small, mean people; servants. Because his renditions are concrete and specific in meaning, the connotation of junzi and xiaoren become narrow and shallow in the target context. In addition, the translator did not distinguish xiaoren from $\min$ ( people) when he rendered the former into people.[12:13.4, p443] He used gentleman to translate junzi and shi( 士) and used a little gentleman to translate xiaoren so that readers may find it is hard to distinguish junzi from shi and even from xiaoren.[8.7,p401] Another problem in the translation of junzi is his willful addition or arrangement of attributives to the head word so that the readers may mistake the translated terms for different references as can be seen in the cases of a wise and good man, a good and wise man and a wise man. On the whole, Gu Hongming presented to the West a wisdom genealogy of junzi and xiaoren. His translation is a deviation from the general understanding of the two words. Just as Li Cunshan[22:p195]said, "The traditional Chinese culture... is different from both the religious culture of ancient India and the West in the Middle Ages. Ours is a culture of ' humanism' that is based on secular life. It is also different from the culture of ancient Greek humanism which is based on wisdom or intelligence. Ours is that of 'moral humanism'."

\subsection{Arther Wayey's Unifying Approach}

Arthur Waley in his version The Analects insisted on the uniformity of translated terms for junzi, but on the variation for xiaoren. For junzi Waley chose gentleman or true( real) gentleman, but for xiaoren, he used several terms including common people (4 times) 、 commoners( 3 times), lesser man, small people, no gentleman, not a gentleman, low walks of life and people of low birth, laying emphasis respectively on social rank, birth, but less on morality and even less on intelligence. Through the multiple translated terms for xiaoren, the meanings and connotations are revealed. But their limited assistance is felt to the translation of junzi in terms of meaning revealment. The unifying approach with the term gentleman for junzi not only sacrifices the richness of meanings in junzi, but also leads to replacement of the original meanings with those of the translated term in target culture. It helps maintain the identity of the English culture and further consolidate the coherence and homogeneity of the culture. [35:p68] The terms for xiaoren such as commoners or common people implies that a junzi is a person that is an elite high above the general public. Besides, Waley did not distinguish xiaoren from other terms with similar meanings such as min (common people or the ruled 民 ), shuren (the common people, commoners 庶 人).[38:2.20,p21;16.2,p219] If xiaoren is translated into common people or commoners, it should be assumed that almost all people are xiaoren, even including Confucius himself. But we at once realize that this assumption will not be accepted because of the wrong choice of perspective in translation. Waley's translations of xiaoren are likely to lead people to understand the two keywords as the classification of the social members. Therefore, the translated term gentleman and any of the translated terms for xiaoren here 
cannot form the morality genealogy like that of junzi and xiaoren in the source culture.

\subsection{Gentleman as the Translated Term for Junzi}

There is still a need to have more comments on the choice of gentleman as a translated term for junzi. Like Waley, Legge and $\mathrm{Gu}$ Hongming also used gentleman as one of the translated terms for junzi. The question is, to what extent the two words are corresponding to and incompatible with each other? In terms of their origin, both of them refers to nobility. They have experienced almost the same evolution, that is, from nobility to non-nobility, from social status to morality, from exteriority to interiority, but the two are endowed respectively with different political, social or aesthetic ideals And both of them gradually denote the moral character of a person. Both carry the gender markers in themselves. But the difference are also obvious. In Western cultural history,no opposite term were specially developed for gentleman like xiaoren the opposite of junzi. Non-gentleman is passable, but boob, cad, sneak are narrow and despicable. As an ideal character of ancient Chinese society, more than two thousand years ago Confucius began to cut off its intrinsic link with birth, position, status and wealth. The word gentleman derived from Latin origin, meaning a man of good family. As late as $14^{\text {th }}$ century, John Ball shouted his seditious slogan "When Adam delved and Eve span, Who was then the Gentleman?" The meaning of noble person in the word were popular in the times of Geoffrey Chaucer. In the West, manuals on gentlemanly civility with emphasis on self-discipline in contrast to valor in the past occurred as late as 16 the century and sociability gained upper hand in the high society in the $18^{\text {th }}$ century. In $17^{\text {th }}$ century, it was still associated with blood because the title of gentleman could not be granted by the king if the person did not carry the blue blood. [4:p467]An ideal gentleman had more desire for private space which helped to cultivate his individuality. Different from junzi, gentleman has never thoroughly ended the strong ties with birth, position, wealth, gender and even markers (mainly refers to coat of arms). Junzi now does not only restricted to the male and the singular. During the Renaissance, Europeans began to argue about what a true gentleman was decided upon, birth or virtue. Even as late as the $19^{\text {th }}$ and the early $20^{\text {th }}$ century, heraldists still insisted that a true gentleman should be proved by coat of arms. Gentleman is more external than junzi in terms of forbearance, politeness, etc. there are two aspects concerning language difference: gender and number. The disillusion of Pip's gentlemanship in Great Expectation by Charles Dickens(1861)comes from his lack of the support of nobles and wealth. They will never be removed unless the term is replaced. [37:p742] In all, junzi is a anthropomorphized sublimate realm and the cultivation process is to follow or model on an ideal personality whose aesthetic values lie in its spirituality. In contrast, gentleman is a social identity or a title of honor with strong flavor of birth, and its cultivation is to follow the fashion of high society. And its aesthetic values lie in the external character with valor, self-discipline, forbearance, civility, modesty etc. Shenshi(绅士)is one word which is often adopted to translate gentleman. In recent decades, some new versions of The Analects have come off the press which adopted unifying approach but still translate junzi with gentleman. [20]

Cultural keywords like Junzi promise an open-ended corresponding translated terms for themselves. $\mathrm{Xu}$ Yuanchong( X.Y.Z)[40] emphasized the intellectual aspect of junzi and xiaoren, and diversified both. He coined a special term intelligentleman [40:1.2,p1] and designed the term a cultured man for junzi, and a uncultured man for xioaren. [40:4.10,p15] Tyldesley[41] simply used junzi in pinyin to transliterate the keyword but diversify xiaoren. Some prefer use other established one similar to gentleman such as man of honor throughout the text without reflection on the externality of its sense. [24]The significance of the transliteration lies in presentation of Chineseness in cultural identity. Similarly, David Hall \&Roger Ames developed a new translated term exemplary person for junzi to combine self-cultivation with political responsibility on the ground that junzi cultivates himself in reverential carefulness to ease others. They endorse the judgment that junzi before Confucius times means persons in power seeking for the improvement of moral character while Confucius tended to lay the emphasis on self-cultivation for higher position[14:p184]. They criticized that Legge's "superior man" and Waley's "gentleman" veiled the political responsibility of junzi. But as the keyword is a complete whole with multiple facets, the term exemplary person highlights the external character of practicing political proprieties on the one hand, and concealed to some extent the internal traits on the other. We admit exemplary person suits junzi well in some way, but it is also reasonably suitable for translating shengren (sage, as Ames \&Rosemont translated) in every way.

\section{Rethinking of and Inspiration from the Translated Terms}

\subsection{Cultural Keywords: Translatability and Untranslatability}

The translation of cultural keywords is both possible and impossible. It is possible because of the multifold meanings in the keyword and for the same reason it is impossible. Zero translation or transliteration admits the untranslatability, and seems to be able to solve all the problems including that of cultural identity, but it stops translators from interpreting potential meanings in the keyword, hence return the right of interpretation to the target readers. It is hard to decide whether it is a loss or a gain in terms of cultural construction and intercultural communication.

To find out or create a term in English that contains all the 
above-said aspects in junzi is difficult or even impossible, not only because translated terms are unable to set up all the referential, social, or associative meanings, but also because there will always be intrinsic elements left. The priorities of personality traits in junzi vary from translator to translator. Once the priority is determined, it is the guideline in deciding terms for junzi and the relevant keywords. This can be illuminated by French writer and translator André Gide when he was expounding the features of word meaning. He said, "The common case is, even though a word has its clear reference or so-called definite equivalent in other languages, both the word and its equivalent, have a halo of association, or indistinct reminiscence, or an overtone, which are different from each other in the respective language culture. This very difference is impossibly delivered to the target culture. " [11:p206] One of the translation theorists suggests that "polysemous or suggestive expressions must not be reduced to monosemous or explicit ones at the excuse of illuminating the readers." [39:p98]But the problem is that it is hard or even impossible to reproduce an ideal term without reducing some meanings of the keyword. "The suggestiveness of the sayings and writings of the Chinese philosophers is something that can hardly be translated. When one reads them in translation, one misses the suggestiveness; and this means that one misses a great deal."'[9:p14] The concomitant of the translatability of a cultural keyword is its untranslatability. When commenting on the translation principles of Chinese and Western theoretical terms, a Chinese philosopher Li Youzheng said, "It is quite impossible to 'discover' or 'find' the most appropriate ready-made method to translate...Because of the dissimilarities between Chinese and Western systems of abstract concepts, there is no one-to-one correspondence in the theoretical discourses." [23:p342] The readers may be very likely to grasp this facet of the multiple meanings of the word but being screened from getting to know the rest meanings. Just as Fung Yu-lan said, “...the translation may convey only one idea, while as a matter of fact, the original may contain many other ideas besides the one given by the translator. The original is suggestive, but the translation is not, and cannot be. So it loses much of the richness inherent in the original.”[9:p14] This helps to explain why junzi are translated into so many terms by means of diversifying. Translators tend to make the suggestive expression articulate by translating one facet of the term.

The problem of translatability and untranslatability is a problem more cultural than linguistic. It does not exist in one cultural keyword but exists in the network which is woven with the keyword and other keywords. This process is complicated in that the translator can never safely translate a cultural keyword without taking the risk of coming into conflicts with its relevant keywords in the source culture. The translation of cultural keywords, different from that of sci-tech words, needs a negotiation or dialogical space. It is different from the "tertium comparationis" which is based on the presupposition of interlingual invariant and which may lead to the oversimplification of the keyword meanings. I would call it a third space practical and dynamic, which consists of the interrelationships among the three factors: words, ideas and events. The translator enters the third space through language( words) to evoke and renovate (events) the potential meanings (ideas) in the keyword and the meaning relationships with other relevant cultural keywords. And the ideal translator for cultural keywords is a scholar at the same time. Just as Roger T. Ames and Henry Rosemont[1:p164] told us that language translation and understanding of thoughts should be equally emphasized.

Further research leads us to realize that cultural keyword translation is a process of difference discovery and meaning revelation with a historical vision. Two theorists, Kuhn[18] and Quine[32], help us to confirm the necessity and rationality of this situation. The insightful explication the term "Incommensurability" by Kuhn[19] diachronically affirmed the comparability, and even communicability in cultural communication despite of the lack of common measurements. The untranslatability in cultural keywords has turned into a problem of translatability in the sense of comparability. Similarly, the theory of "Indeterminacy of Translation" by Quine[32:p26-79] synchronically verified the relativity of translation between cultures. All translators' terms for the same cultural keyword are agreeable with the meaning potentials of the keyword, but each of the translators presents a different conceptual scheme for the word. It would be more constructive to combine the two theories when considering the problematics of translating cultural keywords. The difficulty of translation of junzi and xiaoren in The Analects lies in its incommensurability and meaning uncertainty. But the two words are interpretable and translatable in the sense of relativism.

\subsection{The Rational Analysis of Adopting the Two Approaches}

Suggestiveness is the stylistic feature in the writings with cultural keywords. In translation there exists a contradiction of pursuits between suggestiveness and articulateness. They "are, of course, incompatible. The more an expression is articulate, the less it is suggestive-just as the more an expression is prosaic, the less it is poetic."[9:p12] However they are two ideals a translator may strive to realize by adopting unifying approach or diversifying approach. The two approaches lead to the uniformity of translated terms and the diversity of translated terms. It is safe to say that the uniformity of them comes from the motivation of maintaining the suggestiveness of the keyword and the cultural identity of the source culture in the target culture, and that the diversity of translated terms results from the interaction between the suggestiveness of the keyword and the articulateness of the translator's approach in translation. But the practice shows each of the two approaches may turn into their opposite directions. The former descends to an assistant action to increase the number of diversified terms for the keyword while the latter ruins the suggestiveness of 
the original word and by presenting the keyword with contextually variant terms distances the readers from the conceptual paradigm of the source culture. Furthermore, if the translator uses domesticating method in the unifying approach, he or she contributes to the maintenance of the identity of the target culture, not that of the source culture, as what Arthur Waley did.

But they too help to bring about the same result: the diversity of a cultural keyword in the target culture. The unifying approach tends to choose or create terms that are more comprehensive in meaning, such as superior man, or exemplary person, or gentleman in the case of junzi. Each of these translations is one of many different interpretations of the keyword and each emphasizes one facet of the keyword. Unifying approach depends on broader or general context such as cultural or academic background while the diversifying approach is mainly oriented to specific context so that different terms are adopted for the same cultural keyword. With the unifying approach, the translator is comparatively invisible once the term for the keyword is chosen or designed. With the diversifying approach, the translator who acts as an active interpreter is more visible in the text. As the activity of translating cultural keywords is carried out in the contradiction of suggestiveness and articulateness, the choice of approaches is a matter of gain and loss. Therefore, there is always rationality in either choice of the two approaches.

The translation of one keyword amounts to that of a chain of signifiers if the source text is likened to a chain of signifiers and its translation to a chain of the signified as can be seen in the saying that "translation is a process by which the chain of signifiers that constitutes the source-language text is replaced by a chain of signifiers in the target language which the translator provides on the strength of an interpretation."[34:p17] But the signifier is only the phonological sound or appearance of a word. Therefore, the translation of cultural keywords are not that simple like the relationship between the signifier and the signified. But this metaphor covers up one fact that may experience unavoidable undertranslation or overtranslation. Some terms may impose upon the cultural keyword extra meanings that it inherently does not have. Besides, Junzi, as a name or term, does not offer any more meaning than "prince", "princely man or "son of the king", and it is solid and concrete in name but illusive in sense or connotation. The cultural keyword is "concrete and corporeal in form", but "formless in signification." [25:p552] Some translators adopted the diversifying approach for the purpose of articulateness of the keyword with suggestiveness. However, articulateness may brings about new suggestiveness. He Xin[15], a historian and economist quoted a Buddhist with such saying "One interpretation definitely begets a masking; whenever an interpretation occurs, a masking grows; the interpretation goes along with the masking." This is an endless pursuit.

From the perspectives of Chinese art and philosophy, the translation of cultural key words is that of the relationship of name/term and reality which is different from that of signifier and the signified. The dichotomy of linguistic signs is that between names(or terms; ming 名) and reality ( or actualities; shi 实). A cultural keyword as a name intrinsically has meanings as well as its phonological traits. "If names be not correct, language is not in accordance with the truth of things." [21:p263,264] A translator thinks more about how a name matches its reality. He or she is motivated to think more of their concord with the cultural actualities which help determine the potential meanings of the keywords. Chinese art and philosophy seek uncertainty from certainty, uniformity from differences, infiniteness from finiteness, motivationality from arbitrariness, hence the translator believe the name or term is meaningful and strives to translate the untranslatable.

\subsection{The Relationship Between the Two Approaches}

In terms of cultural communication, both unifying and diversifying approaches are necessary in mutual understanding. The former helps to establish the cultural identity as far as the cultural symbols are concerned while the latter has the function of revealing the multifold meanings of the keyword. They are interactive and complementary. There is no reason to think one approach is superior to the other. Each translator can choose unifying approach or diversifying approach in one mission. But, if each translator chooses unifying approach and each translate the keyword with a different term, then each translation diversifies the word once in the same cultural text. Anyway the choice of one approach from the two is significant because it stands for the translator's understanding of the keyword and accordingly the source culture. The two approaches work together in the progressive formation of the cultural identity in the target culture.

\subsection{The Relationships of the Two Approaches with Other Approaches}

There are no corresponding relationships between the two approaches on the one side and literal translation vs. liberal translation, or domesticating method vs. foreignizing method on the other. In the case of junzi, most terms for it are based on interpretative and domesticating approaches. Different from its counterpart xiaoren, literal and foreignizing translations (including transliterations) of junzi are rare no matter which of the approaches the translator may take. On the one hand, it shows the resistance against literal and foreignizing translation in the English world. On the other, it reveals the hermeneutic inclination. In terms of orientation, there are three types of translated terms which represent three approaches: domesticated terms, foreignized terms and innovated or coined terms like intelligentleman for junzi. In fact, the number of last two are much smaller, most of them fall in the first category. 


\section{Conclusions}

The translation cultural keywords is can be examined from multi-dimensional perspectives. Cultural and ideological factors may influence the purpose of the translator and hence shape the style of a version by adopting the unifying approach or diversifying approach. But the final determinant is the suggestiveness of the keywords which tend to refuse to be translated and by both the two approaches more translated terms are produced on the one hand and more thoughts and meanings are revealed through the source text. The significance of discussing the two approaches is multiple. One is to let the target readers know that cultural keywords may be temporarily transferred with one term or may be concealed with multiple terms for each keyword in one translated work. The other point is that Chinese way of looking at the problem is more constructive and thought-provoking, and different from the theories based on deconstructionism. It is a process of meaning reconstruction and revealment. And there is no real translation of the keywords without referring to the cultural histories of thoughts and concepts. To translate the keywords is to realize what Daiyun Yue called "reciprocal cognition"[43:p35]Translated terms are the result of reanalyzing and rethinking of the source and target histories of culture. The cooperation of the two approaches are needed in intercultural communication though an individual translator may choose one approach in a certain work. Therefore the methodology is not like that of natural sciences, but that of humanistic hermeneutics. The translation is both an academic dialogue and an adventure of thoughts.

\section{REFERENCES}

[1] Ames, Roger T. and Henry Rosemont, Jr., translators. The Analects of Confucius: A Philosophical Translation (Analects), tr. with intro. by Roger T. Ames and Henry Rosemont, Jr., New York: Bollantine Books; 1998.

[2] Bian Lihong. On the Translation of "Junzi". Foreign Language Research. 2006. 131(4): pp94-99

[3] Chen Weiping. The Multiple Theoretical Connotations of Confucius 'Junzi' Theory, In Shan Chun, chief editor. International Confucianism Studies.No.17.Beijing: Jiuzhou Island Publishing House; 2010. p78.

[4] Evans, Ivor H, editor. Brewer's Dictionary of Phrase and Fable. Beijing: World Publishing Corporation; 1993.

[5] Fan Wenlan. General History of China. Beijing: People's Publishing House; 1978.

[6] Fang Weigui. Historical Semantics and Conceptual History: Some Thoughts on Definitions, Methods and Related Problems. In: Feng Tianyu et al, editors. Cultural Changes of Word Meanings. Wuhan: Wuhan University Press; 2007.

[7] Fang Weigui. Fundamentals of Conceptual History Research Methodology: Also on Related Problems. In: Huang Xingtao, editor. New Historiography: A new Starting Point of Cultural History,Vol.3. Beijing: Zhonghua Book Company.; 2009.

[8] Fei Hsiao-tung. China's Gentry: Essays in Rural-Urban Relations. Chicago: University of Chicago Press;1945. $\mathrm{p} 25,45,176$

[9] Fung Yulan. A Short History of Chinese Philosophy. Derk. Bodde, editoror. New York: The Free Press and London: Collier Macmillan Publishers; 1948.

[10] 10. Fung Yulan. History of Chinese Philosophy: The Period of the Philosophers (from the Beginnings to Circa 100 B.C.), with introduction, notes, bibliography and index. Derk. Bodde, translator. Peiping : Henri Vetch; 1937.

[11] Gide, Andr Paul Guillaume. Collected Works of André Paul Guillaume Gide . Vol.(literary theories). Gui Yufang, Wang Wenrong, translators. Guangzhou: Huacheng Publishing House;2001.

[12] Gu Hongming, translator. The Discourses and Sayings of Confucius. In: Huang Xingtao, et al, editors and translators. Collected Works of Gu Hongming. Haikou: Hainan Publishing House; 1996.

[13] Guo Shangxing. A History of Chinese Confucianism. Shanghai: Shanghai Foreign Language Education Press; 2011.

[14] Hall, David L. \& Roger T. Ames: Thinking Through Confucius. Albany: State University of New York Press; 1987

[15] He Xin. An Introduction to Universal Evolution Logic: Ontological Basis for Thinking Logic. Beijing: Current Affairs Publishing House; 2005. p176

[16] Hong Ye et al, editors. Index of Confucius Analects and The Book of Mencius. Shanghai: Shanghai Classics Publishing House; 1986

[17] Khu, John B. et al, translators. The Confucius Bible Book I. Analects. Beijing: World Affairs Press; 1997.

[18] Kuhn, Thomas S . The Structure of Scientific Revolutions. 3rd ed. Chicago: University of Chicago Press; 19621970/1996, p103, 12,148,150,198.

[19] Kuhn,Thomas S. Commensurability, Comparability, Communicability. In: P. D. Asquith \& T. Nickles, editors. Proceedings of the Biennial Meeting of the Philosophy of Science Association. Vol. 2. Chicago: The University of Chicago Press; 1982, pp. 669-688.

[20] Lau,D.C.,translator. Confucius: The Analects. With modern Chinese version by Yang Bojun. Bejing: Zhonghua Book Company; 2008.

[21] Legge, James, translator. Confucian Analects, the Great Learning \& the Doctrine of the Mean. New York: Dover Publications, Inc.; 1893/1971.

[22] Li Cunshan. Confucius and the Paradigm of Thought in Chinese Philosophy. In: Shan Chun, editor. International Confucianism Studies.No.17.Beijing: Jiuzhou Island Publishing House; 2010.

[23] Li Youzheng. History and Ethics: A Dialogue Between Chinese and the Western Hermeneutics. Beijing: China Renmin University Press; 2008. 
[24] Lin Wusun, translator. Getting to Know Confucius: A New Translation of The Analects. Beijing: Foreign Language Press; 2010.

[25] Liu Ying.The Reconstruction of Keywords and the Formation of Discourse Order in Translation and Interpretation: A Case Study of Fenggu. In: Guan Shijie, editor Order ,Fairness, Justice and Social Development in Human Civilizations. Symposium of Beijing Conference of Harvard-Yenching Alumni in China 2007.Beijing: Beijing University Press. 2009.

[26] Luo Zhiye, (English) translator. The Book of History. With Modern Chinese version by Zhou Bingjun. Changsha: Hunan Publishing House; 1997. p306,307

[27] Luo Zhufeng, chief editor. Hanyu Da Cidian (Comprehensive Chinese Word Dictionary). Vol.1. Reduced edition. Shanghai: Hanyu Da Cidian Publishing House; 1997. p1546.

[28] Pang, Tze Yau, translator. Lun Yu of Confucius. Shenyang: Volumes Publishing Company;2005.

[29] Peng Feng. The Gentleman(Junzi)'s Personality and the Aesthetic paradox in Confucian attainment. Journal of Shaanxi Normal University, 2009; 38(4):18-23.

[30] Pohl, Karl-Henz. Translating the Untranslatable: Approaches to Study Chinese Culture. in Gao Jianping \& Wang Keping, editors. Aesthetics and Culture: East and West. Hefei: Anhui Education Publishing House; 2006. p107.

[31] Qian Mu. A New Interpretation of Confucius Analects. Beijing: The Joint Publishing Company Ltd; 2002. p152

[32] Quine,Willard Orman. Word and Object. Cambridge: The Massachusetts Institute of Technology Press; 1960,p26-79

[33] Tylor, Charles. The Ethics of Authenticity. Cambridge: Harvard University Press; 1992.
[34] Venuti, Lawrence. The Translator's Visibility: A History of Translation. London: Routledge; 1995.

[35] Venuti, Lawrence. The Scandals of Translation: Towards an Ethics of Differences. London: Routledge; 1998.

[36] Wang Guowei. Comments on Gu Hongming's Translation of the Doctrine of the Mean. In: Yao Ganming \& Wangyan, editors. Collected Works of Wang Guowei. Vol.3. Beijing: China Literature and History Publishing House; 1997.

[37] Wang Taiqing. On the Creativity of Translation. In: Wang Taiqing, translator. Dialogues of Plato. Beijing: The Commercial Press; 2004. Appendix

[38] Waley, Arther, translator. The Analects. Beijing: Foreign Language Teaching and Research Press,1998.

[39] $\mathrm{Xu}$ Jun. Introduction to Translation Theories. Beijing: Foreign Language Teaching and Rearch Press; 2009.

[40] Xu Yuanchong(X.Y.Z), translater. Confucious Modernized:Thus Spoke the Master. Beijing: High Education Press; 2005.

[41] Yu Dan. Confucius From the Heart: Ancient Wisdom for Today's World. Esther Tyldesley, translator. Beijing: Zhonghua Book Company; 2006.

[42] Yu Zhihui. The Scholar After the Style of Junzi and Poetry Education. Beijing: Sanlian Bookstore; 2005.

[43] Yue Daiyun.The Clash of Civilization and Its Future. In: Guan Shijie, editor. East Asia's View on World Culture. Beijing: Beijing University Press; 2004.

[44] Yue Daiyun. Resolving Cultural Conflicts with Oriental Wisdom. In: Guan Shijie. Eastern Civilization in Globalization. Beijing: Beijing University Press; 2007. 